\title{
Revolutionology: an introduction
}

\author{
Robert Bird ${ }^{1}$
}

Published online: 19 June 2018

(C) Springer Nature B.V. 2018

The essays gathered for this double issue of Studies in East European Thought originated as contributions to a conference The Bolshevik Contagion held at the Neubauer Collegium of the University of Chicago on 2-3 November 2017. The purpose of the conference was severalfold. First, it was intended to commemorate the 1917 revolutions in Russia (and subsequent upheaval elsewhere in Europe) by re-examining some of their central theoretical texts. Second, the conference sought to investigate new paradigms for intellectual history (or the history of ideas) as a discipline uniting history, philosophy, political theory and critical theory. As the inaugural event of the long-term project Revolutionology: Media and Networks of Intellectual Revolution, the conference asked to what extent a major historical event can be correlated with intellectual sources and, concomitantly, how a close examination of these sources as events and as material artefacts can help us to understand the ideas as historical forces.

Participants, drawn from a broad array of academic disciplines, were asked to present a paper on a single text from the intellectual legacy of Bolshevism, combining close textual analysis with a consideration of the text as the material node of an intellectual network. Selections ranged from The Communist Manifesto (James Farr) to The ABC of Revolution (Sheila Fitzpatrick) and History and Class Consciousness (Martin Jay) and Mikhail Lifshits's Marx and Engels about Art (David Riff). Given the variety of participants' disciplinary backgrounds, approaches ranged from the philological (i.e., an analysis of the text's internal structure and argument or of its adaptation in new texts) to those of social history or political theory. The result was a memorably intense and fertile discussion among participants and with the audience, the results of which are reflected in the essays published herewith.

Robert Bird

bird@uchicago.edu

1 The University of Chicago, Chicago, USA 
In addition to this double issue of Studies in East European Thought, the presentations from The Bolshevik Contagion have provided data for an on-line project that maps the generation and dissemination of revolutionary texts in space and time. These interactive maps will be publicly available on the site: <voices.uchicago.edu/ revolutionology $>$. Examples of these maps serve as illustrations to the essays by Sheila Fitzpatrick and Robert Bird.

Gathering a network of scholars of revolutionary ideas, The Bolshevik Contagion built on the work begun at an October 2014 conference The Russian Intellectual Revolution, organized by Sergei Zenkin in Moscow, and an April 2017 rejoinder Intellectual Revolution at the University of Chicago. ${ }^{1}$ Revolutionology continues with the conferences Philosophy of Revolution (21-22 May 2018) and 1968 Decentered (19-20 October 2018), which investigate further moments and nodes in the development of revolutionary intellectual networks (both synchronic and diachronic). It is hoped that both conferences will result in the publication of at least selected contributions, helping to build a material basis for the new science of revolutionology.

\footnotetext{
${ }^{1}$ The proceedings of the 2014 conference have been published as: Russkaia intellektual'naia revoliutsiia 1910-1930-kh gg. Eds. Sergei Zenkin and E. P. Shumilova. Moscow: NLO, 2016. 